\title{
Article \\ The Assessment of the Maximum Heat Production and Cooling Effectiveness of Three Different Drill Types (Conical vs. Cylindrical vs. Horizontal) during Implant Bed Preparation-An In Vitro Study
}

\author{
Stefan Ihde ${ }^{1}$, Bartosz Dalewski ${ }^{2}\left(\mathbb{O}\right.$ and Łukasz Pałka ${ }^{3, *}$ (1) \\ 1 Clinic for Maxillofacial Surgery, University of Belgrade, 11-000 Belgrade, Serbia; ihde1962@gmail.com \\ 2 Department of Dental Prosthetics, Pomeranian Medical University, 70-111 Szczecin, Poland; \\ bartosz.dalewski@pum.edu.pl \\ 3 Private Dental Practice, 68-200 Żary, Poland \\ * Correspondence: dr.lpalka@gmail.com
}

\section{check for}

updates

Citation: Ihde, S.; Dalewski, B.; Pałka, $€$. The Assessment of the Maximum Heat Production and Cooling Effectiveness of Three Different Drill Types (Conical vs. Cylindrical vs. Horizontal) during Implant Bed Preparation-An In Vitro Study. Appl. Sci. 2021, 11, 9961. https://doi.org/10.3390/ app11219961

Academic Editor: Gabriele Cervino

Received: 27 September 2021

Accepted: 23 October 2021

Published: 25 October 2021

Publisher's Note: MDPI stays neutral with regard to jurisdictional claims in published maps and institutional affiliations.

Copyright: (c) 2021 by the authors. Licensee MDPI, Basel, Switzerland. This article is an open access article distributed under the terms and conditions of the Creative Commons Attribution (CC BY) license (https:/ / creativecommons.org/licenses/by/ $4.0 /)$.

\begin{abstract}
The aim of this experimental study was to verify thermal diffusion differences, by measuring the maximum temperature achieved with different drill shapes. Synthetic bone blocks of type I density made from solid rigid polyurethane (PUR) foam were used to perform the drilling procedures. The experiment was conducted at three different rotation speeds: 800, 3000 and $5000 \mathrm{rpm}$. Conical drills (with and without an internal cooling hole) were compared with horizontal drills and disc drills. The temperature during drilling for implant bed preparation was estimated with the use of thermocouples and an infrared (IR) camera. The temperature during drilling with disc cutters for lateral basal implants did not exceed $33^{\circ} \mathrm{C}$ and the temperature decreased in proportion to higher drill speed. The results indicate that the tested design is safe and will not cause bone overheating.
\end{abstract}

Keywords: conical drill; cylindrical drill; cutting disc; cortical bone; dental implants

\section{Introduction}

The impact the temperature has on the remodeling and healing processes of the bone during implant site preparation has been extensively described in the literature [1]. The shape of the drill, its design, fatigue, cooling technique, cooling material, the force applied during drilling and the rotation speed have been considered crucial factors [1]. Different temperature measuring tools have been used to analyze temperature changes including: real time infrared thermography [2], type T thermocouples [3], type K thermocouples [4], thermographic digital camera [5], digital thermometer [6], type $\mathrm{K}$ thermocouples and digital thermometer [7].

Eriksson and Albrektsson [8] reported that the temperature generated by the drill while preparing the implant site should not exceed $47^{\circ} \mathrm{C}$ for more than $1 \mathrm{~min}$, as such overheating causes irreversible osteonecrosis. Other reported factors influencing the overall success of osseointegration are implant biocompatibility, design, surface, condition of the host bed, surgical technique, and loading [9].

El-Kholey et al. [10] suggested that the number of drills used during implant bed preparation has no significant influence on the bone temperature increase following either conventional or simplified drilling procedure. What is more, the drilling technique (continuous versus intermittent) did not cause rise in the temperature and subsequent bone overheating (i.e., above $47^{\circ} \mathrm{C}$ ) [11]. Nevertheless, there are some techniques which utilize bone collected from the drill as a graft material and while applying them it is recommended not to use cooling water and a decreased drilling speed [6].

Polyurethane (PUR) foam blocks have been commonly used in experimental studies replacing cadaver or animal bone specimens [4,7,12-17]. According to Schim [18] and 
Horn [19] polyurethane foam is a good alternative for human cancellous bone as it displays similar mechanical properties and may be used as a medium for implant testing. Horak et al. [17] conducted experimental studies to evaluate its mechanical properties (temperature, strain and density) and reported that it is not only suitable for mechanical investigations but also for investigations involving surgical instruments that generate heat. Moreover, this type of foam meets the ASTM F-1839-08 "Standard Specification for Rigid Polyurethane Foam for Use as a Standard Material for Testing Orthopaedic Devices and Instruments" which makes it an ideal material for comparative testing of bone screws and other medical devices and instruments.

The aim of the present in vitro study was to measure and verify the maximum temperature of the drills used for placing crestal and lateral basal implants, with different drill shapes. We hypothesized that disc cutters for lateral basal implants, regardless of their design, would not exceed the temperature of $47^{\circ} \mathrm{C}$ and could be safely used while preparing the implant bed site. Therefore we aimed to evaluate disc cutters safety protocol in terms of maintaining non-hazardous bone temperature levels.

\section{Materials and Methods}

Polyurethane (PUR) foam blocks (Sawbones, Vashon Island, WA, USA) used in the present studies simulate the clinical conditions encountered during implant bed preparation. Artificial bone blocks made from solid rigid polyurethane foam (Figure 1) are similar to human D1 bone i.e., primarily dense cortical bone according to Misch's classification [20] and offer uniform and consistent physical properties that eliminate the variability encountered when testing with human cadaver bone. For this experiment foam blocks with a thickness of $10 \mathrm{~mm}$, a width of $15 \mathrm{~mm}$, a length of $15 \mathrm{~mm}$, and density of $0.64 \mathrm{~g} / \mathrm{cm}^{3}$ (40 pounds per cubic foot $=40 \mathrm{pcf}$ ) were used.

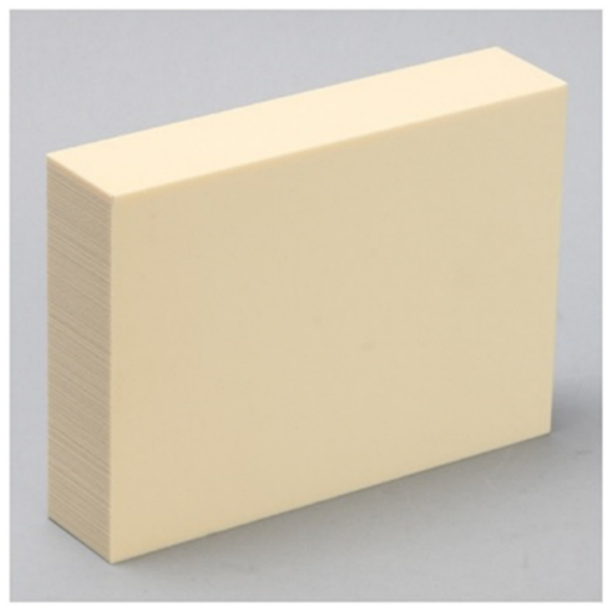

Figure 1. The polyurethane (PUR) block used for drills testing.

The experiment was carried out with eight different drills from the same manufacturer (Ihde Dental, Gommiswald, Switzerland), i.e.:

Group 1: Conical drills with (drill 1) and without (drill 2) a hole for standard implants with conical core.

Group 2: Cylindrical drills Ø $2.0 \mathrm{~mm}$ (drill 3), Ø $2.5 \mathrm{~mm}$ (drill 4) and with cutting disc $\varnothing 7 \mathrm{~mm}$ (drill 5).

Group 3: Cutting discs Ø8 mm (drill 6), Ø9 mm (drill 7) and Ø10 mm (drill 8) as presented in Figure 2. 


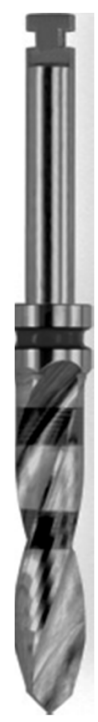

Drill 1 conical drill without a hole
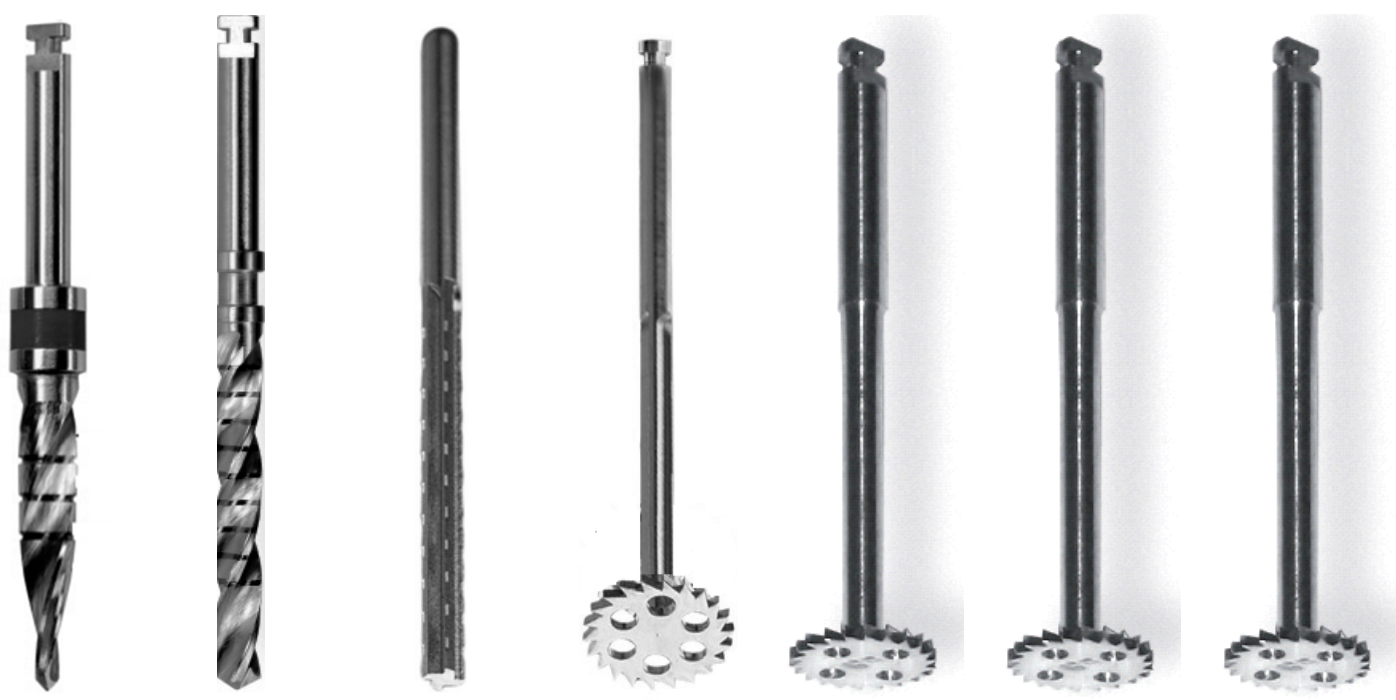

$\begin{array}{ccc}\text { Drill 2 } & \text { Drill 3 } & \text { Drill 4 } \\ \text { conical } & \text { cylindrical } & \text { cylindrical } \\ \text { drill with } & \text { drill Ø2.5 } & \text { drill Ø2 } \\ \text { a hole } & \mathrm{mm} & \mathrm{mm}\end{array}$

Drill 5

cylindrical drill with a cutting disc $\varnothing 7 \mathrm{~mm}$
Drill 6 cutting disc $\varnothing 8 \mathrm{~mm}$
Drill 7 cutting disc $\varnothing 9 \mathrm{~mm}$
Drill 8 cutting disc $\varnothing 10 \mathrm{~mm}$

Figure 2. Specific drills for the experimental investigation.

The experimental setup, as shown in Figure 3, consisted of the surgical drilling machine (Implantmed, W\&H, Bürmoos, Austria) fixed in a three- axis movement CNC machine. A PUR block with thermocouples to detect the temperature changes inside the foam was fixed on a table in the same horizontal axis as the surgical drilling machine (drills 1 and 2) and in the same drilling direction. An IR camera (FLIR T1020, FLIR Systems, Wilsonville, OR, USA) was mounted in front of the PUR block to record the temperature at the cutting edge of the experimental drills while perforating the PUR block.

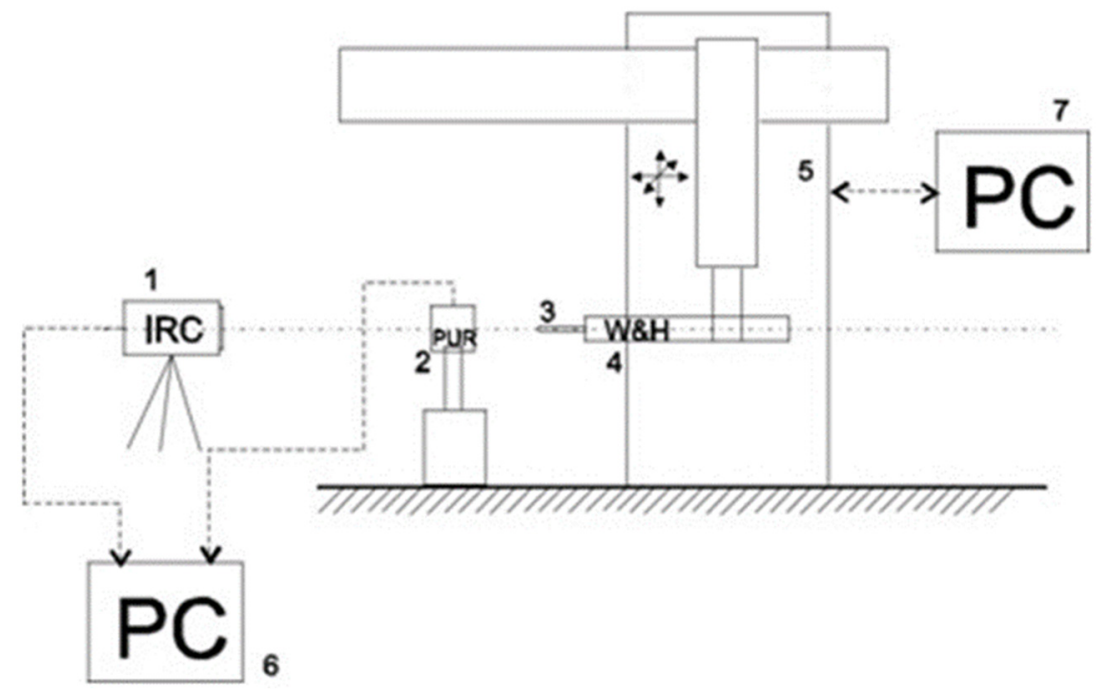

Figure 3. Experimental setup: 1-Infrared (IR) camera with PC connection; 2-PUR block with installed thermocouples connection to PC; 3 -measured drill; 4-W\&H surgical drilling machine; 5-drilling machine fixation and three axis movement; 6 and 7-PC for drill movement controlling and recording data from IR camera and thermocouples. 
In this study, a load of $2 \mathrm{~kg}$ was applied, in accordance with the procedures described by Misir et al. [21]. For the cutting disc measurement, drills 3, 4, 5, 6, 7 and 8 were installed in the vertical axis with the rotary function of the CNC machine, as shown in Figure 4. In front of the PUR block the FLIR T1020HD thermal camera was mounted to record the temperature in the cutting edge while drilling [18]. The experiment was done at three different rotational speeds of 800, 3000 and $5000 \mathrm{rpm}$. Each measurement combination of the drill type and rpm was performed only with cooling, for which the surgical drilling machine cooling system was used with water as a cooling medium. Cooling water was showered on the drill or cutting disc while performing experiment. Three holes were drilled with each drill to test the samples of the polyurethane foam.
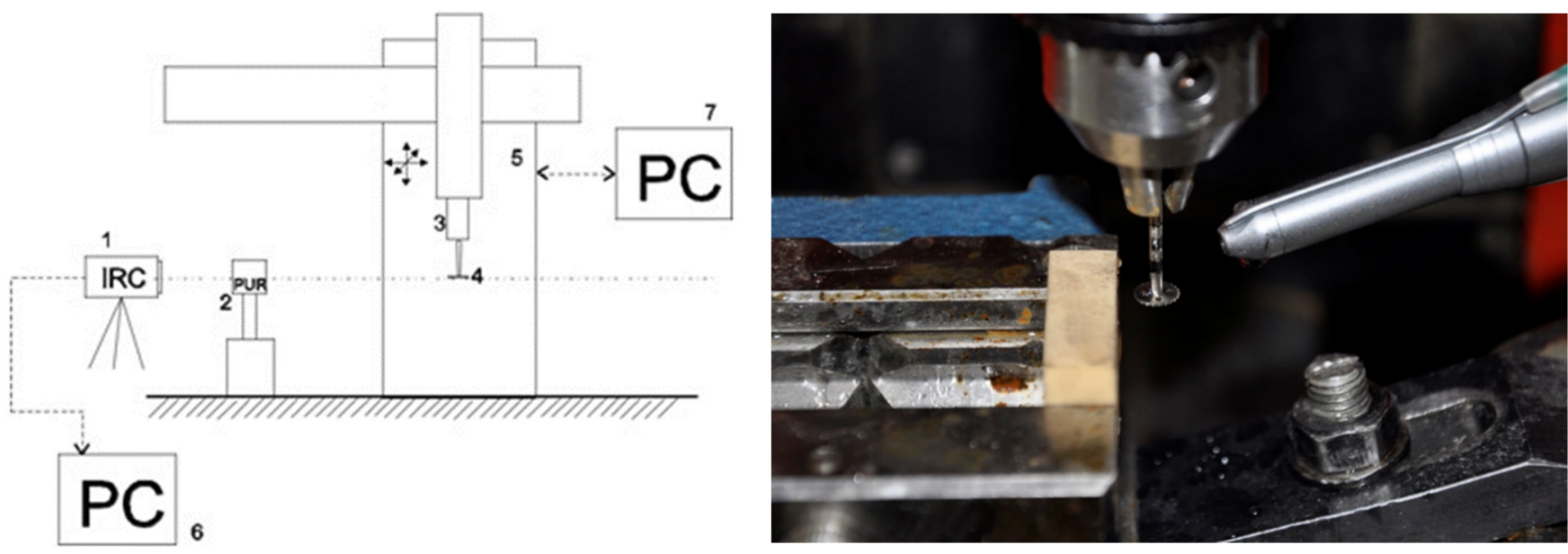

Figure 4. An experimental setup: 1-IR camera with connection to PC 2-PUR block; 3-vertical axis of CNC machine with rotary function; 4 -measured drill (cutting disc); $5-\mathrm{CNC}$ machine with three axis movement; 6 and 7 - PC for drill movement controlling and recording data from IR camera.

Drills 1 and 2 were used in horizontal axis $2 \mathrm{~mm} / 30 \mathrm{~mm} / \mathrm{min}$ axial movement of a drill (drilling) and then the load was reduced by moving the drill $1 \mathrm{~mm}$ back (with an axial movement of a drill $500 \mathrm{~mm} / \mathrm{min}$ ). Using this interrupted drilling technique it was possible to drill through the PUR block. According to some researchers one of the benefits of this type of interrupted drilling protocol is lower heat production [22]. Interrupted drilling protocol $5 \mathrm{~mm} / \mathrm{min}$ was also used for drills 3, 4, 5, 6, 7 and 8 (drilling was $2 \mathrm{~mm}$ by $5 \mathrm{~mm} / \mathrm{min}$ and then $1 \mathrm{~mm}$ back by $500 \mathrm{~mm} / \mathrm{min}$ ).

\section{Results}

The data obtained from the experiments are presented in Table 1 and Figure 5. The results of the investigation showed that drill 1 without a hole (with increasing groove helix) generated the temperature of $38.4^{\circ} \mathrm{C}$ at the speed of $800 \mathrm{rpm}$ with cooling. When the speed increased the heat production increased accordingly, but the maximum values were still acceptable $\left(\mathrm{T}_{3000} \max =61.5^{\circ} \mathrm{C}\right.$ and $\left.\mathrm{T}_{5000} \max =63.8^{\circ} \mathrm{C}\right)$.

On the other hand, drill 2 with a hole showed that even if the interrupted drilling protocol was used, the temperatures were higher than those produced by drill 1 . The maximum temperatures generated by the drill were $\mathrm{T}_{5000} \max =75.4^{\circ} \mathrm{C}, \mathrm{T}_{3000} \max =65.5^{\circ} \mathrm{C}$ and at the speed of $800 \mathrm{rpm}$ the drill was completely blocked inside the PUR foam interrupting the experiment (Figure 6). 
Table 1. The maximum temperature detected on the thermocouple for conical drills and cutting discs during three revolutions. Version with cooling.

\begin{tabular}{|c|c|c|c|}
\hline Drill Number & Type & Revolutions (rpm) & $\begin{array}{c}\text { Maximum } \\
\text { Temperature }\left({ }^{\circ} \mathrm{C}\right)\end{array}$ \\
\hline \multirow{3}{*}{1} & \multirow{3}{*}{ conical } & 800 & 38.4 \\
\hline & & 3000 & 61.5 \\
\hline & & 5000 & 63.8 \\
\hline \multirow{3}{*}{2} & \multirow{3}{*}{ conical } & 800 & $\mathrm{~N} / \mathrm{A}$ \\
\hline & & 3000 & 75.4 \\
\hline & & 5000 & 65.5 \\
\hline \multirow{3}{*}{6} & \multirow{3}{*}{ cutting disc } & 800 & 27.4 \\
\hline & & 3000 & 27.3 \\
\hline & & 5000 & 26.5 \\
\hline \multirow{3}{*}{7} & \multirow{3}{*}{ cutting disc } & 800 & 33.4 \\
\hline & & 3000 & 29.5 \\
\hline & & 5000 & 28.3 \\
\hline \multirow{3}{*}{8} & \multirow{3}{*}{ cutting disc } & 800 & 33.2 \\
\hline & & 3000 & 29.4 \\
\hline & & 5000 & 28.3 \\
\hline
\end{tabular}

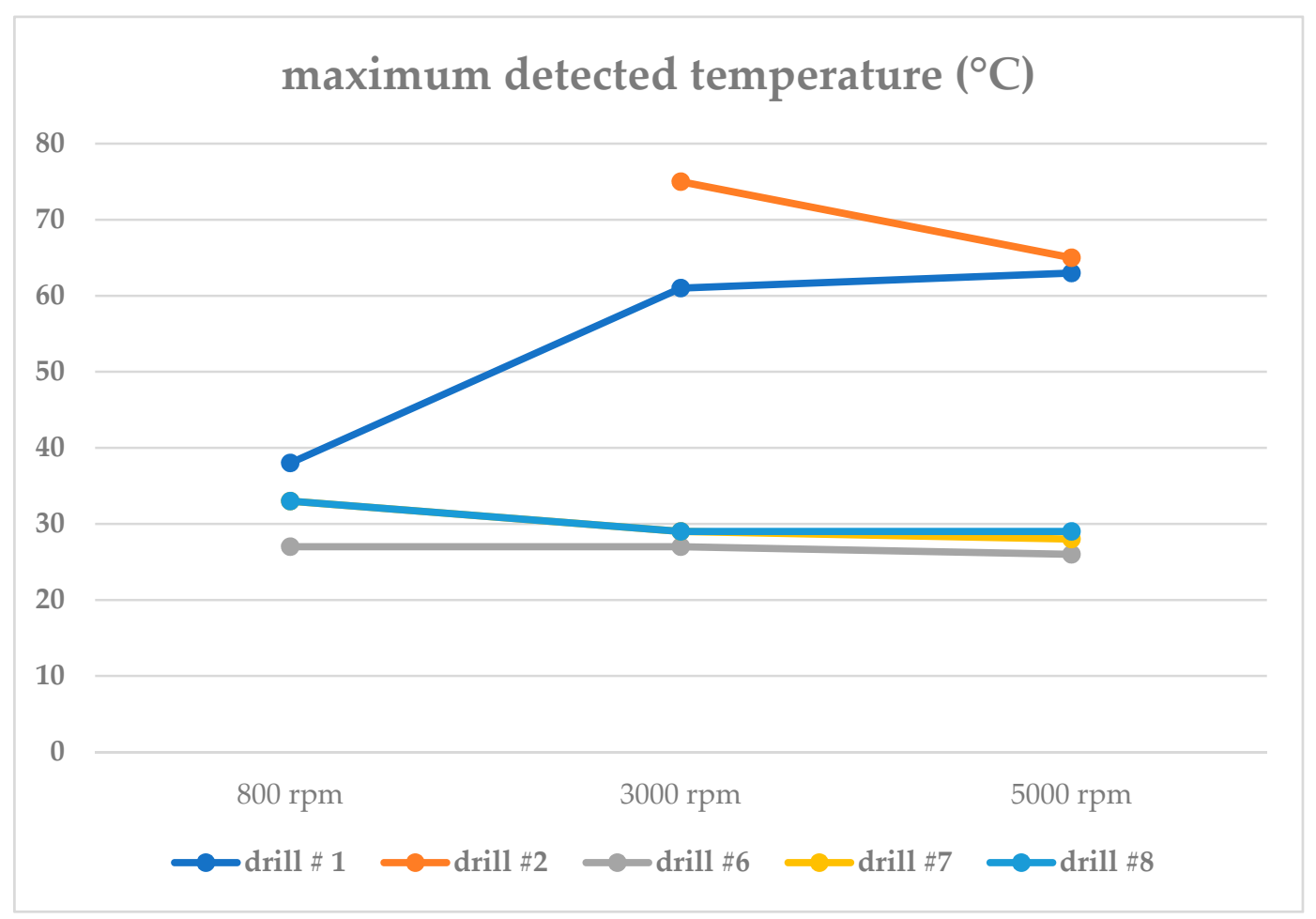

Figure 5. The maximum temperature detected on the thermocouple for conical drills and cutting discs during three revolutions. Version with cooling. 


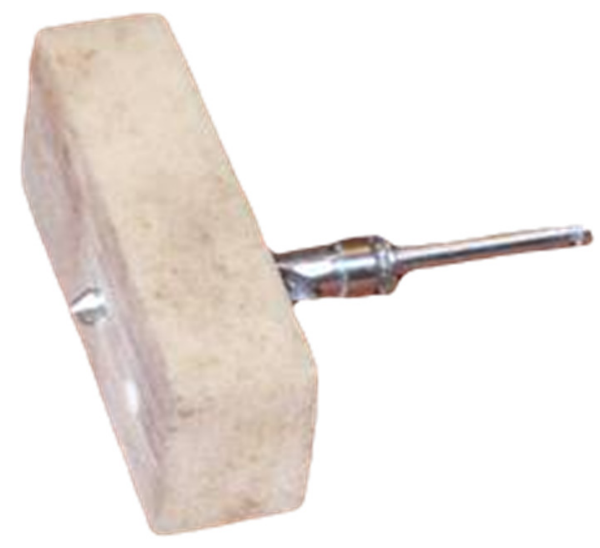

Figure 6. The experiment with conical drill \#2 was interrupted when it got blocked in the PUR foam at the speed of $800 \mathrm{rpm}$.

Drills 3 and 4, which are usually used to cut material in radial direction, had been moving $5 \mathrm{~mm} / \mathrm{min}$ towards a PUR block. In this case, it was shown that this experimental setup with interrupted drilling protocol, cooling and drill speed of $3000 \mathrm{rpm}$ was not suitable for making the hole in the radial direction of the PUR foam as drill \#3 fractured and the experiment with drill \#4 was stopped so that the drill would not break (Figure 7).
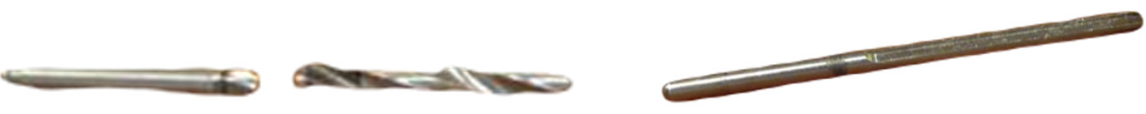

Figure 7. On the left, fractured drill 3 and on the left drill 4.

For drills with cutting discs $(5,6,7,8)$ a similar experimental setup as for drills 3 and 4 was used, as shown in Figure 3. It could have been observed that the disc-drill was self-carrying cooling medium into the depth of the slot (Figure 8).
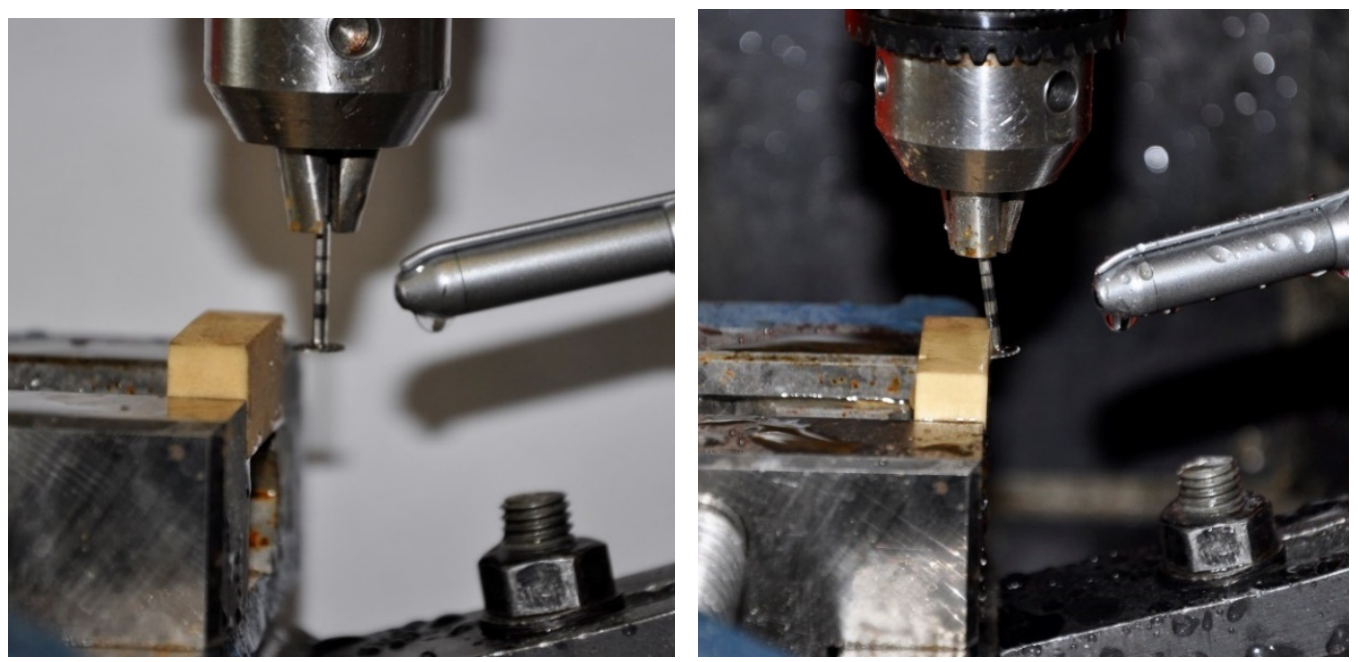

Figure 8. On the left, cutting disc carrying cooling medium into the depth of the slot. On the right, drill 5 bent at $3000 \mathrm{rpm}$.

Drill 5 cut the PUR foam very easily but with the vertical part, which was in this case made for radial cutting. The vertical part of this drill that is used for making the slot, did not manage to cut the PUR foam with the $5 \mathrm{~mm} / \mathrm{min}$ cutting movement and $3000 \mathrm{rpm}$ rotational speed. The drill 5 then bent and the experiment was stopped so as not to destroy the drill. 
For cutting discs 6,7 , and 8 the vertical slots with $2.7 \mathrm{~mm}$ thickness were first milled as shown in Figure 9a (drills number 7 and 8), and then horizontal slots were made by the cutting discs (Figure $9 \mathrm{~b}$ ). The horizontal slots were made by interrupted drilling protocol and with $5 \mathrm{~mm} / \mathrm{min}$ horizontal cutting speed.

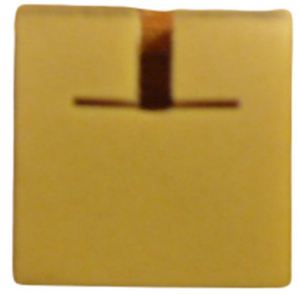

(a)
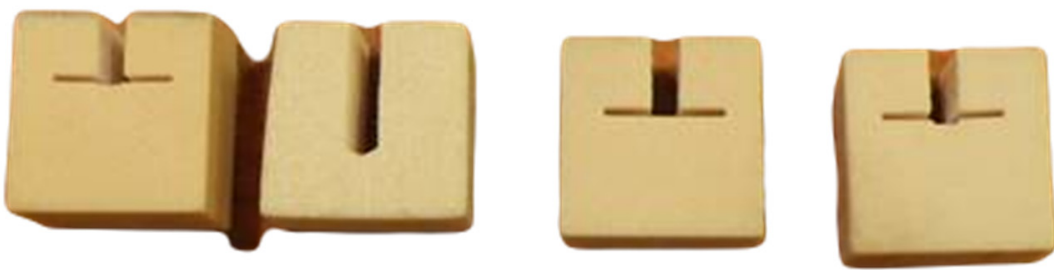

(b)

Figure 9. (a). Vertical, $2.7 \mathrm{~mm}$ - thick slot for cutting discs. (b). Horizontal and vertical slot from cutting disc \#6 in PUR foam.

Experiments with drills 6, 7, and 8 were made with cooling, interrupted drilling protocol and the maximum measured temperature did not exceed $30^{\circ} \mathrm{C}$ (Table 1, Figure 2).

The results obtained for axial conical drills (drills 1 and 2) with the interrupted drilling protocol and cooling were similar to the results after drilling at one time (uninterrupted drilling protocol), i.e., the produced heat was about $10-15 \%$ lower. With increased rotation speed, the maximum temperatures measured by IR camera increased for both tested drills. The drill without a hole provided better results than the drill with a hole (2) even if the cooling medium was flowing through the drill's hole.

Experiments with drills number 3 and 4 showed that the experimental setup with interrupted drilling, cooling and the drill speed of $3000 \mathrm{rpm}$ was not suitable for making the slot in the radial direction in the PUR foam. Drill 3 fractured and the experiment with drill 4 was stopped so that the drill would not break. Experiments with drills 6, 7, and 8 were made with cooling, interrupted drilling protocol and the maximum measured temperature was below $30^{\circ} \mathrm{C}$.

\section{Discussion}

While preparing implant bed various factors need to be taken into consideration, including the drill's shape, drilling technique, cooling material and drilling speed and torque, as well as the implant system used [23-26]. In some systems there is a tendency to minimize the number of drills to simplify the procedure and lower the overall costs $[27,28]$. In other systems, a large number of drills allows for safe and precise bed preparation in risky recipients [29]. As far as the heat production is concerned, Watanabe et al. [30] reported that maximum heat temperature without irrigation was higher than that with irrigation, which contradicts our observations, whereas Gehrke et al. [23] suggested that the double irrigation technique produced a significantly smaller increase in the temperature in the cortical bone during both continuous and intermittent drilling movement. It is worth highlighting that while using disc drills the temperature decreased in proportion to the increasing drilling speed, which, so far, has not been described in the literature. This may have some clinical implications as disk implants are used in cranio-facial surgery for epithesis anchorage in auricular and orbital regions [31,32]. Since in these regions there 
is a close vicinity of anatomical structures and the bone often undergoes irradiation, high temperature during bed preparation may be undesirable.

Gaspar et al. [25] showed that the effects of the bone preparation by low speed drilling $(50 \mathrm{rpm})$ without irrigation and conventional drilling $(800 \mathrm{rpm})$ with irrigation are similar, which means that both drilling techniques are successful in keeping bone cells alive. In our study, one drill fractured during drilling and the experiment with drill 4 was stopped so that the drill would not break. It might have been due to the fact that the PUR foam is harder than the real bone of the mandible, or cylindrical part of these drills were not sharp enough for radial drill cutting. In our opinion the radial movement $5 \mathrm{~mm} / \mathrm{min}$ is very slow to be performed in clinical environment while drilling into the patient's bone.

In this study, the drill without a hole (1) provided better results than the drill with a hole (2) even if the cooling medium was flowing throughout the hole. These results confirm findings presented by Strbac et al. [15] for twist drills with $2 \mathrm{~mm}$ diameter and $10 \mathrm{~mm}$ drilling depth. They reported the lowest temperature change of $20.45^{\circ} \mathrm{C}$ for external irrigation in comparison with internal irrigation where the temperature rose to $28.30^{\circ} \mathrm{C}$. We have concluded that the amount of metal-mass in the drill helps to absorb and distribute the heat better than the through-and-through irrigation of the cutting part of the drill.

There are also numerous articles regarding the importance and differences between simplified and conventional drilling techniques in regards to their numbers, which show that the outcome on the bone is the same [10]. Jimbo et al. [33] evaluated the combined effect of drilling sequence and implant diameter. It turned out that the simplified technique did not influence bone formation. What is more, studies conducted by El-Kholey and Elkomy [34] showed that a simplified drilling technique generates as much heat as the conventional one. To prove their hypothesis they used 80 implants with 2 different diameters placed in bovine ribs.

Guazi et al. [35] tested implants placed in sites prepared with a simplified protocol with one drill and multiple conventional drilling steps. Their results showed that both drilling techniques are successful, but single-bur technique was less time consuming and caused less pain. Additionally, Sarendranath et al. [36] compared simplified protocols with conventional ones in terms of biological response. The authors concluded that the simplified procedure provides biological outcomes comparable to those achieved following the conventional one. El-Kholey et al. [10] evaluated 120 implant site preparations with three different diameters following simplified and conventional drilling procedures and measured the bone temperature using K-type thermocouple and a sensitive thermometer before and after each drill was used. They concluded that there was no significant difference in temperature increase when implants were prepared by either of methods.

\section{Conclusions}

Basing on the above results, we may conclude that since the temperature during drilling with disc cutters for lateral basal implants did not exceed $33^{\circ} \mathrm{C}$ and, what is more, it decreased in proportion to higher drill speed, this design is safe and will not cause bone overheating. Thus, a high drilling speed with irrigation for disc cutters seems to be safe protocol for lateral basal implant osteotomy site preparation.

Author Contributions: Conceptualization, S.I. and Ł.P.; methodology, S.I.; software, S.I.; validation, S.I., Ł.P. and B.D.; formal analysis, Ł.P.; investigation, S.I.; resources, S.I.; data curation, B.D.; writingoriginal draft preparation, Ł.P.; writing-review and editing, S.I., Ł.P. and B.D.; supervision, Ł.P. All authors have read and agreed to the published version of the manuscript.

Funding: This research received no external funding.

Institutional Review Board Statement: Not applicable.

Informed Consent Statement: Not applicable.

Data Availability Statement: Data are available upon request from the corresponding author.

Conflicts of Interest: The authors declare no conflict of interest. 


\section{References}

1. Mishra, S.; Chowhardy, R. Heat generated by dental implant drills during osteotomy-A review: Heat generated by dental implant drills. J. Indian Prosthodont. Soc. 2014, 14, 131-143. [CrossRef] [PubMed]

2. Lucchiari, N.; Frigo, A.C.; Stellini, E.; Coppe, M.; Berengo, M.; Bacci, C. In Vitro Assessment with the Infrared Thermometer of Temperature Differences Generated During Implant Site Preparation: The Traditional Technique Versus the Single-Drill Technique. Clin. Implant. Dent. Relat. Res. 2014, 18, 182-191. [CrossRef]

3. Calvo-Guirado, J.L.; Delgado-Peña, J.; Maté-Sánchez, J.E.; Mareque Bueno, J.; Delgado-Ruiz, R.A.; Romanos, G.E. Novel hybrid drilling protocol: Evaluation for the implant healing-thermal changes, crestal bone loss, and bone-to-implant contact. Clin. Oral Implant Res. 2015, 26, 753-760. [CrossRef]

4. Oh, J.-H.; Fang, Y.; Jeong, S.-M.; Choi, B.-H. The effect of low-speed drilling without irrigation on heat generation: An experimental study. J. Korean Assoc. Oral Maxillofac. Surg. 2016, 42, 9-12. [CrossRef]

5. José, L.F.D.S.; Ruggeri, F.M.; Rucco, R.; Zubizarreta-Macho, A.; Pérez-Barquero, J.A.; Deglow, E.R.; Montero, S.H. Influence of Drilling Technique on the Radiographic, Thermographic, and Geomorphometric Effects of Dental Implant Drills and Osteotomy Site Preparations. J. Clin. Med. 2020, 9, 3631. [CrossRef]

6. Anitua, E.; Carda, C.; Andia, I. A novel drilling procedure and subsequent bone autograft preparation: A technical note. Int. J. Oral Maxillofac. Implants 2007, 22, 309.

7. Salomó-Coll, O.; Auriol-Muerza, B.; Lozano-Carrascal, N.; Hernández-Alfaro, F.; Wang, H.-L.; Gargallo-Albiol, J. Influence of bone density, drill diameter, drilling speed, and irrigation on temperature changes during implant osteotomies: An in vitro study. Clin. Oral Investig. 2020, 25, 1047-1053. [CrossRef]

8. Eriksson, A.; Albrektsson, T. Temperature threshold levels for heat-induced bone tissue injury: A vital-microscopic study in the rabbit. J. Prosthet. Dent. 1983, 50, 101-107. [CrossRef]

9. Albrektsson, T.; Branemark, P.I.; Hansson, H.A.; Lindstrom, J. Osseointegrated titanium implants: Requirements for ensuring a long-lasting, direct bone-to-implant anchorage in man. Acta Orthop. Scand. 1981, 52, 155-170. [CrossRef]

10. El-Kholey, K.E.; Ramasamy, S.; Kumar, S.; Elkomy, A. Effect of simplifying drilling technique on heat generation during os-teotomy preparation for dental implant. Implant Dent. 2017, 26, 888-891. [CrossRef]

11. Di Fiore, A.; Sivolella, S.; Stocco, E.; Favero, V.; Stellini, E. Experimental analysis of temperature differences during implant site preparation: Continuous drilling technique versus intermittent drilling technique. J. Oral Implantol. 2018, 44, 46-50. [CrossRef] [PubMed]

12. Yang, B.; Irastorza-Landa, A.; Heuberger, P.; Ploeg, H.-L. Effect of insertion factors on dental implant insertion torque/energyexperimental results. J. Mech. Behav. Biomed. Mater. 2020, 112, 103995. [CrossRef] [PubMed]

13. Oh, H.J.; Wikesjö, U.M.; Kang, H.-S.; Ku, Y.; Eom, T.-G.; Koo, K.-T. Effect of implant drill characteristics on heat generation in osteotomy sites: A pilot study. Clin. Oral Implant. Res. 2010, 22, 722-726. [CrossRef] [PubMed]

14. Strbac, G.D.; Giannis, K.; Unger, E.; Mittlböck, M.; Watzek, G.; Zechner, W. A novel standardized bone model for thermal evaluation of bone osteotomies with various irrigation methods. Clin. Oral Implant. Res. 2013, 25, 622-631. [CrossRef] [PubMed]

15. Strbac, G.D.; Giannis, K.; Unger, E.; Mittlböck, M.; Vasak, C.; Watzek, G.; Zechner, W. Drilling- and Withdrawing-Related Thermal Changes during Implant Site Osteotomies. Clin. Implant. Dent. Relat. Res. 2013, 17, 32-43. [CrossRef]

16. Gehrke, S.A.; Bettach, R.; Taschieri, S.; Boukhris, G.; Corbella, S.; Del Fabbro, M. Temperature Changes in Cortical Bone after Implant Site Preparation Using a Single Bur versus Multiple Drilling Steps: An In Vitro Investigation. Clin. Implant. Dent. Relat. Res. 2013, 17, 700-707. [CrossRef]

17. Horak, Z.; Dvorak, K.; Zarybnicka, L.; Vojackova, H.; Dvorakova, J.; Vilimek, M. Experimental Measurements of Mechanical Properties of PUR Foam Used for Testing Medical Devices and Instruments Depending on Temperature, Density and Strain Rate. Materials 2020, 13, 4560. [CrossRef]

18. Shim, V.; Boheme, J.; Josten, C.; Anderson, C.J.A.I. Use of Polyurethane Foam in Orthopaedic Biomechanical Experimentation and Simulation, Polyurethane; Fahmina Zafar, F., Ed.; InTech: London, UK, 2012. [CrossRef]

19. Horn, T.J.; Harrysson, O.L.A.; Little, J.P.; West, H.A.; Marcellin-Little, D.J. Design and manufacturing of bone analog models for the mechanical evaluation of custom medical implants. In Proceedings of the 21st Annual International Solid Freeform Fabrication Symposium-An Additive Manufacturing Conference, SFF 2010, Austin, TX, USA, 9-11 August 2010; University of Texas at Austin (freeform): Austin, TX, USA, 2010; pp. 864-875.

20. E Misch, C.; Bidez, M.W. Implant-protected occlusion: A biomechanical rationale. Compendium 1994, 15, 1330-1344.

21. Misir, A.F.; Sumer, M.; Yenisey, M.; Egrioglu, E. Effect of Surgical Drill Guide on Heat Generated from Implant Drilling. J. Oral Maxillofac. Surg. 2009, 67, 2663-2668. [CrossRef]

22. Tuijthof, G.; Frühwirt, C.; Kment, C. Influence of tool geometry on drilling performance of cortical and trabecular bone. Med Eng. Phys. 2013, 35, 1165-1172. [CrossRef]

23. Gehrke, S.A.; Neto, H.L.; Mardegan, F.E. Investigation of the effect of movement and irrigation systems on temperature in the conventional drilling of cortical bone. Br. J. Oral Maxillofac. Surg. 2013, 51, 953-957. [CrossRef] [PubMed]

24. Liu, D.-Y.; Wu, Y.-N.; Peng, W.; Liao, W.-Q.; Wang, Y.-L. The influence of drilling pulling ways and cooling systems on dental implant surgery. Shanghai Kou Qiang Yi Xue Shanghai J. Stomatol. 2014, 23, 149-153.

25. Gaspar, J.; Borrecho, G.; Oliveira, P.; Salvado, F.J.; Dos Santos, J.M. Osteotomy at low-speed drilling without irrigation versus high-speed drilling with irrigation: An experimental study. Acta Med. Port. 2013, 26, 231-236. [PubMed] 
26. Kosior, P.; Kuropka, P.; Janeczek, M.; Mikulewicz, M.; Zakrzewski, W.; Dobrzyński, M. The Influence of Various Preparation Parameters on the Histological Image of Bone Tissue during Implant Bed Preparation-An In Vitro Study. Appl. Sci. 2021, 11, 1916. [CrossRef]

27. Ihde, S.; Pałka, Ł.; Janeczek, M.; Kosior, P.; Kiryk, J.; Dobrzynski, M. Bite Reconstruction in the Aesthetic Zone Using One-Piece Bicortical Screw Implants. Case Rep. Dent. 2018, 2018, 4671482. [CrossRef]

28. Pałka, Ł.R.; Lazarov, A. Immediately Loaded Bicortical Implants Inserted in Fresh Extraction and Healed Sites in Patients with and Without a History of Periodontal Disease. Ann. Maxillofac. Surg. 2019, 9, 371-378. [CrossRef]

29. Gehrke, S.A.; Bettach, R.; Júnior, J.S.A.; Prados-Frutos, J.C.; Del Fabbro, M.; Shibli, J.A. Peri-Implant Bone Behavior after Single Drill versus Multiple Sequence for Osteotomy Drill. BioMed Res. Int. 2018, 2018, 9756043. [CrossRef]

30. Watanabe, F.; Tawada, Y.; Komatsu, S.; Hata, Y. Heat distribution in bone during preparation of implant sites: Heat analysis by real-time thermography. Int. J. Oral Maxillofac. Implant. 1992, 7, 212-219.

31. Ivanjac, F.; Konstantinovic, V.; Lazić, V.; Dordević, I.; Ihde, S. Assessment of Stability of Craniofacial Implants by Resonant Frequency Analysis. J. Craniofacial Surg. 2016, 27, e185-e189. [CrossRef]

32. Vitomir, K.S.; Filip, I.; Vojkan, L.; Igor, Đ.; Lukasz, P. Survival rate of disk and screw-type implants used for the retention of extraoral prostheses. J. Prosthet. Dent. 2020. [CrossRef]

33. Jimbo, R.; Giro, G.; Marin, C.; Granato, R.; Suzuki, M.; Tovar, N.; Lilin, T.; Janal, M.; Coelho, P.G. Simplified Drilling Technique Does Not Decrease Dental Implant Osseointegration: A Preliminary Report. J. Periodontol. 2012, 84, 1599-1605. [CrossRef] [PubMed]

34. El-Kholey, K.E.; Elkomy, A. Effect of the Drilling Technique on Heat Generation During Osteotomy Preparation for Wide-Diameter Implants. Implant. Dent. 2016, 25, 825-828. [CrossRef]

35. Guazzi, P.; Grandi, T.; Grandi, G. Implant site preparation using a single bur versus multiple drilling steps: 4-month post-loading results of a multicenter randomised controlled trial. Eur. J. Oral Implant. 2015, 8, 283-290.

36. Sarendranath, A.; Khan, R.; Tovar, N.; Marin, C.; Yoo, D.; Redisch, J.; Jimbo, R.; Coelho, P.G. Effect of low speed drilling on os-se-ointegration using simplified drilling procedures. Br. J. Oral Maxillofac. Surg. 2015, 53, 550-556. [CrossRef] 